\title{
Comparison of the Elecsys HBsAg II Assay and the Architect Assay for Quantification of Hepatitis B Surface Antigen in Chronic Hepatitis B Patients
}

\author{
Chen-Chih Liao ${ }^{1}$, Chao-Wei Hsu ${ }^{1}$, Po-Wen Gu${ }^{2}$, Chau-Ting Yeh ${ }^{1}$, Shi-Ming Lin ${ }^{1}$, Cheng-Tang Chiu ${ }^{1}$
}

Background: Hepatitis B virus (HBV) infection is one of the infections with a highest prevalence in Taiwan. The most important marker is hepatitis B surface antigen (HBsAg). Using the new generation of HBsAg quantitative assay, HBsAg level may have good correlation with viral activity during different phases of chronic hepatitis B virus infection. This study was conducted to compare two assays of HBsAg level to find if the same results are obtained in HBsAg quantification in treatment-naïve and on-treatment chronic hepatitis B patients.

Methods: $\quad$ Between March 2012 and June 2012, 90 patients with chronic hepatitis B (68 males and 22 females) were assessed using Abbott Architect HBsAg QT and Roche Elecsys HBsAg II assay. HBV DNA was detected by Roche COBAS TaqMan instrument.

Results: $\quad$ HBsAg level measured with Elecsys and Architect assays correlated well in untreated patients $\left(n=53, \gamma_{\mathrm{s}}=0.997\right)$ and on-treatment patients $\left(n=37, \gamma_{\mathrm{s}}=0.988\right)$. BlandAltman analyses of the discrepancies in HBsAg levels showed a bias of $-4.2 \%$ in untreated patients and $-6.2 \%$ in on-treatment patients. Patients with $\mathrm{HBeAg-postive}$ chronic hepatitis B had higher HBsAg level than the ones who were HBeAg negative, and both showed statistical differences. Further, HBV DNA concentration analysis also showed higher viral concentration in $\mathrm{HBeAg}$-positive patients, but it revealed no statistical difference.

Conclusions: There is a significant correlation between Abbott Architect HBsAg QT assay and Roche Elecsys HBsAg II assay. Moreover, HBsAg quantification may potentially provide complementary information about the deduction of the natural course in chronic hepatitis B infection.

(Biomed J 2015;38:250-256)

Key words: hepatitis B, quantification of hepatitis B surface antigen, treatment-naïve chronic hepatitis B

$\mathrm{H}^{\mathrm{c}}$ epatitis B virus (HBV) infection is a public health problem worldwide. There are more than 350 million HBV carriers in the world. ${ }^{[1]}$ The prevalence of $\mathrm{HBV}$ carriers

\begin{abstract}
At a Glance Commentary
Scientific background of the subject

Previously, HBsAg served as a qualitative diagnostic marker for hepatitis B infection. Quantitative serum HBsAg assays, including Abbott Architect and Roche Elecsys HBsAg assay, have been developed recently. Several recent studies suggest that quantification of HBsAg may be useful for clinical staging of chronic hepatitis B.
\end{abstract}

\section{What this study adds to the field}

The study presented revealed significantly good correlation between Abbott Architect and Roche Elecsys HBsAg assays. HBsAg quantification may potentially provide complementary information about the deduction of the natural course in chronic hepatitis $\mathrm{B}$ infection.

is $10-20 \%$ in high prevalence areas (Southeast Asia, China, sub-Saharan Africa). ${ }^{[2]}$ In Taiwan, HBV is one of the infectious diseases of highest prevalence. People with chronic

\footnotetext{
From the ${ }^{1}$ Department of Gastroenterology and Hepatology, Chang Gung Memorial Hospital at Linkou, Chang Gung University College of Medicine, Taoyuan, Taiwan; ${ }^{2}$ Department of Laboratory Medicine, Chang Gung Memorial Hospital at Linkou, Chang Gung University College of Medicine, Taoyuan, Taiwan

Received: Feb. 18, 2014; Accepted: Sep. 4, 2014

Correspondence to: Dr. Chao-Wei Hsu, Department of Gastroenterology and Hepatology, Chang Gung Memorial Hospital at Linkou.

5, Fusing St., Gueishan, Taoyuan 333, Taiwan (R.O.C.). Tel: 886-3-3281200 ext. 8107; Fax: 886-3-3272236;

E-mail: hsu2406@adm.cgmh.org.tw
}

DOI: $10.4103 / 2319-4170.143485$ 
hepatitis B infection have an increased risk of developing cirrhosis or hepatocellular carcinoma. The estimated worldwide mortality is $0.5-1.2$ million deaths per year. ${ }^{[3]}$

Hepatitis B surface antigen (HBsAg), being a reflection of the transcriptional activity of cccDNA (covalently closed circular DNA) and integrated HBV DNA sequence, is produced through a complex mechanism. Previously, HBsAg served as a qualitative diagnostic marker for hepatitis B infection. Recently, quantitative serum HBsAg assays have been developed. ${ }^{\left[{ }^{[4,5]}\right.}$ Several recent studies suggest that quantification of HBsAg (qHBsAg) may be useful for clinical staging of chronic hepatitis B. ${ }^{[6,7]} \mathrm{HBsAg}$ levels are highest during the immune-tolerant phase, when there are high levels of HBV replication, and lowest in the inactive (low replicative immune control) phase..$^{[8-10]}$

The aim of this study is to compare the two assays, Abbott Architect and Roche Elecsys II, and check whether the same results are obtained in the level of HBsAg in chronic hepatitis B patients, and to correlate the levels with the level of HBV DNA in HBeAg-positive or HBeAg-negative, treatment-naïve chronic hepatitis $\mathrm{B}$ patients.

\section{METHODS}

\section{Patients and samples}

This study was a cross-sectional study. From March 2012 to June 2012, a total of 90 chronic HBV-infected patients were enrolled in this study [Table 1], which consisted of 68 males and 22 females, with a median age of 49.2 years (range 20.5-71.7 years). The patients signed informed consent and the study was conducted under the approval of Institutional Review Board, Chang Gung Memorial Hospital, Taiwan. Fifty-three of the patients were treatment-naïve and 37 of them were under treatment with interferon-based therapy or nucleos ( $t$ ) ide analogs. The baseline characteristics of treatment-naive patients are listed in Table 2 and the characteristics of patients during treatment are listed in Table 3. All patients were recruited from one medical center, Chang Gung Memorial Hospital, Lin-Kou, Taiwan. The time for checking HBsAg levels during treatment varied widely, especially our patients treated with Interferon-based or nucleos(t) ides analogs therapy. In the group of on-treatment patients, patients' HBsAg levels were measured with both assays at the same time.

\section{HBsAg quantitation and HBV DNA}

The Elecsys HBsAg assay (Roche Diagnostics GmbH, Mannheim, Germany) is a two-step sandwich chemiluminescent microparticle immunoassay. Briefly, the assay uses two biotinylated monoclonal HBsAg-specific capture antibodies together with a mixture of biotinylated and ruthenium-labeled polyclonal anti-HBsAg detection antibodies to form a sandwich complex with serum HBsAg. This complex is then bound to streptavidin-coated

Table 1: Patient characteristics

\begin{tabular}{lccc}
\hline & All patients $(N=90)$ & Treatment-naïve $(n=53)$ & On-treatment $(n=37)$ \\
\hline Age, years & $49.2(20.5-71.7)$ & $48.2(27.5-71.7)$ & $50.8(20.5-65.1)$ \\
Male, $n(\%)$ & $68(75.6)$ & $37(69.8)$ & $31(83.8)$ \\
ALT (U/l) & $28(10-1041)$ & $26(10-203)$ & $34(12-1461)$ \\
Liver cirrhosis, $n(\%)$ & $10(11.1)$ & $4(7.5)$ & $6(16.2)$ \\
HBeAg $(+), n(\%)$ & $14(15.6)$ & $8(15.1)$ & $6(16.2)$ \\
HBsAg (IU/ml) & & & 0.256 \\
Elecsys assay & $717.9(0.05-139,000)$ & $480.2(0.05-41,565)$ & $760.1(0.05-139,000)$ \\
Architect assay & $710.0(0.05-100,315)$ & $513.4(0.05-55,805)$ & $751.0(0.05-100,315)$
\end{tabular}

Median values for age, ALT, and HBsAg levels. Abbreviations: ALT: Alanine aminotransferase; HBeAg: Hepatitis B e antigen; HBsAg: Hepatitis B surface antigen

Table 2: Characteristics of $\mathrm{HBeAg}$-positive and -negative treatment-naïve patients

\begin{tabular}{|c|c|c|c|c|}
\hline & All patients $(n=53)$ & HBeAg positive $(n=8)$ & HBeAg negative $(n=45)$ & $p$ \\
\hline Age, years & $48.2(27.5-71.7)$ & $34.3(27.5-46.8)$ & $49.4(30.3-71.7)$ & 0.001 \\
\hline Male, $n(\%)$ & $37(69.8)$ & $6(75)$ & $31(68.9)$ & 0.798 \\
\hline ALT (U/l) & $26(10-203)$ & $38(20-203)$ & $24(10-159)$ & 0.036 \\
\hline HBV DNA (106 IU/ml)* & $0.02975(0.000033-499.5)$ & $1.015505(0.000033-499.5)$ & $0.02315(0.001025-1.246)$ & 0.270 \\
\hline \multicolumn{5}{|l|}{ HBsAg (IU/ml) } \\
\hline Elecsys assay & $480.2(0.05-41,565)$ & $8934.5(2525-41,565)$ & $239.1(0.05-12,803)$ & $<0.001$ \\
\hline Architect assay & $513.4(0.05-55,805)$ & $13,182.5(2890-550,805)$ & $193.1(0.05-15,685)$ & $<0.001$ \\
\hline
\end{tabular}

*29 of all patients $(n=53), 5$ of HBeAg-positive patients, and 24 of HBeAg-negative patients have available HBV DNA data. Median values for age, ALT, HBV DNA, and HBsAg levels. Abbreviations: HBeAg: Hepatitis B e antigen; ALT: Alanine aminotransferase; HBV DNA: Hepatitis B virus deoxyribonucleic acid; HBsAg: Hepatitis B surface antigen 
Table 3: Characteristics of HBeAg-positive and -negative on-treatment patients

\begin{tabular}{|c|c|c|c|c|}
\hline & All patients $(n=37)$ & HBeAg positive $(n=6)$ & HBeAg negative $(n=31)$ & $p$ \\
\hline Age, years & $50.8(20.5-65.1)$ & $34.2(20.5-53.3)$ & $51.8(31.5-65.1)$ & 0.003 \\
\hline Male, $n(\%)$ & $31(83.8)$ & $5(83.3)$ & $26(83.9)$ & 0.984 \\
\hline ALT (U/L) & $34(12-1461)$ & $231(14-1461)$ & $26(12-251)$ & 0.011 \\
\hline \multicolumn{5}{|l|}{$\operatorname{HBsAg}(\mathrm{IU} / \mathrm{ml})$} \\
\hline Elecsys assay & $760.1(0.05-13,900)$ & $10,241.5(29.96-139,000)$ & $657.3(0.05-3884)$ & 0.004 \\
\hline Architect assay & $751.0(0.05-10,031)$ & $14,680.5(39.35-100,315)$ & $648.0(0.05-3685.4)$ & 0.004 \\
\hline
\end{tabular}

Median values for age, ALT, and HBsAg levels. Abbreviations: HBeAg: Hepatitis B e antigen; ALT: Alanine aminotransferase; HBsAg: Hepatitis B surface antigen

microparticles and, subsequently, ruthenium chemiluminescence is detected. ${ }^{[11]}$ Results from the Elecsys HBsAg assay were generated in cut-off index and converted to WHO IU/ml.

The Architect assay (Abbott Diagnostics, Abbott Park, IL, USA) was performed following manufacturer's recommendations. After 1:100 dilution with the serum diluent provided by the manufacturer, samples with $\mathrm{HBsAg}$ levels $>250 \mathrm{IU} / \mathrm{ml}$ were retested at a dilution of 1:500 and 1:1000. Samples with HBsAg levels $<0.05 \mathrm{IU} / \mathrm{ml}$ at 1:100 dilution were retested undiluted. The Abbott Architect HBsAg assay is calibrated to give the results in IU/ml. ${ }^{[12]}$

HBV DNA was analyzed by COBAS TaqMan HBV Test (Roche Molecular Diagnostics Products, USA). The lower limit of detection was $20 \mathrm{IU} / \mathrm{ml}$.

\section{Statistical methods}

The data were presented as median and range values. Differences between subgroups were analyzed using Mann-Whitney U-test. Statistical significance was defined as a $p$ value of less than 0.05. The linear regression model, Chi-square test, Spearman's rank correlation coefficient (denoted as $\gamma_{s}$ ), and Bland-Altman analysis were used to analyze the correlation between Elecsys assay and Architect assay. The data for Bland-Altman analysis were transformed to $\log (10) \mathrm{IU} / \mathrm{ml}$. The bias was calculated as a percentage $(\%)$ of difference between two methods according to the formula: (Architect - Elecsys) 100/average. Statistical analyses were performed using SPSS 17.0 statistical software and Prism 6.0 (GraphPad Software, Inc, CA, USA).

\section{RESULTS}

HBsAg levels in the serum samples from 90 patients with chronic hepatitis B were assessed in both Architect and Elecsys HBsAg assays, and the patients' characteristics are shown in Table 1. The HBV DNA levels were also measured at the same time. There was a significantly good correlation between the Architect and Elecsys HBsAg assays in untreated patients $(n=53)$ and on-treatment patients $(n=37)$ with linear regression model, Spearman's rank correlation coefficient (denoted as $\gamma_{\mathrm{s}}$ ) [Figure 1], and Bland-Altman analysis [Figure 2]. Moreover, HBsAg levels measured with the two assays correlated well in treatment-naïve patients $\left(n=53, \gamma_{\mathrm{s}}=0.997\right)$ and on-treatment patients $(n=37$, $\left.\gamma_{\mathrm{s}}=0.988\right)$ [Figure 1]. Bland-Altman analyses of the discrepancies in HBsAg levels between the Elecsys and the Architect assays showed a bias of $-5.0 \%$ in all patients, $4.2 \%$ in untreated patients, and $-6.2 \%$ in on-treatment patients. These study results were compatible with previous research studies which reported a good correlation between quantitative HBsAg measurements conducted with the Architect and the Elecsys assays. ${ }^{[4,5]}$

We analyzed the 53 treatment-naïve patients and divided them into $\mathrm{HBeAg}$-positive and $\mathrm{HBeAg}$-negative groups [Table 2]. In Roche Elecsys assay, the median HBsAg level was $480.2 \mathrm{IU} / \mathrm{ml}$, with a significantly higher level in $\mathrm{HBeAg}$-positive than in $\mathrm{HBeAg}$-negative patients (median 8934.5 vs. $239.1 \mathrm{IU} / \mathrm{ml}, p<0.001$ ). In Abbott Architect assay, the median level was $513.4 \mathrm{IU} / \mathrm{ml}$, with a significantly higher level in $\mathrm{HBeAg-positive} \mathrm{than} \mathrm{in}$ HBeAg-negative patients (median 13,182.5 vs. $193.1 \mathrm{IU} / \mathrm{ml}$, $p<0.001$ ) [Figure 3]. The median of HBV DNA level was lower in $\mathrm{HBeAg}$-negative than in $\mathrm{HBeAg}$-positive patients $\left(0.02315 \times 10^{6}\right.$ vs. $\left.1.015505 \times 10^{6} \mathrm{IU} / \mathrm{ml}, p=0.258\right)$. However, it revealed no significant difference between $\mathrm{HBeAg}$-positive and HBeAg-negative groups, which might be due to the small sample size (HBV DNA level was detected and available in 29 patients, 5 of $\mathrm{HBeAg}$-positive patients and 24 of $\mathrm{HBeAg}$-negative patients).

We also analyzed all the parameters in on-treatment patients, except HBV DNA level [Table 3]. The median $\mathrm{HBsAg}$ level was significantly lower in HBeAg-negative than in $\mathrm{HBeAg}$-positive patients in both Architect and Elecsys HBsAg assays. The HBV DNA data of on-treatment patients were almost of low titer or undetectable.

Furthermore, $\mathrm{HBeAg}$-positive treatment-naïve patients were found to be younger, which was compatible with a natural history of chronic hepatitis B infection. We assigned treatment-naïve patients into two groups of age less than 40 years $(n=17)$ as immune tolerance/clearance phase and greater than or equal to 40 years $(n=36)$ as residual inactive phase [Table 4]. We applied two quantitative methods 


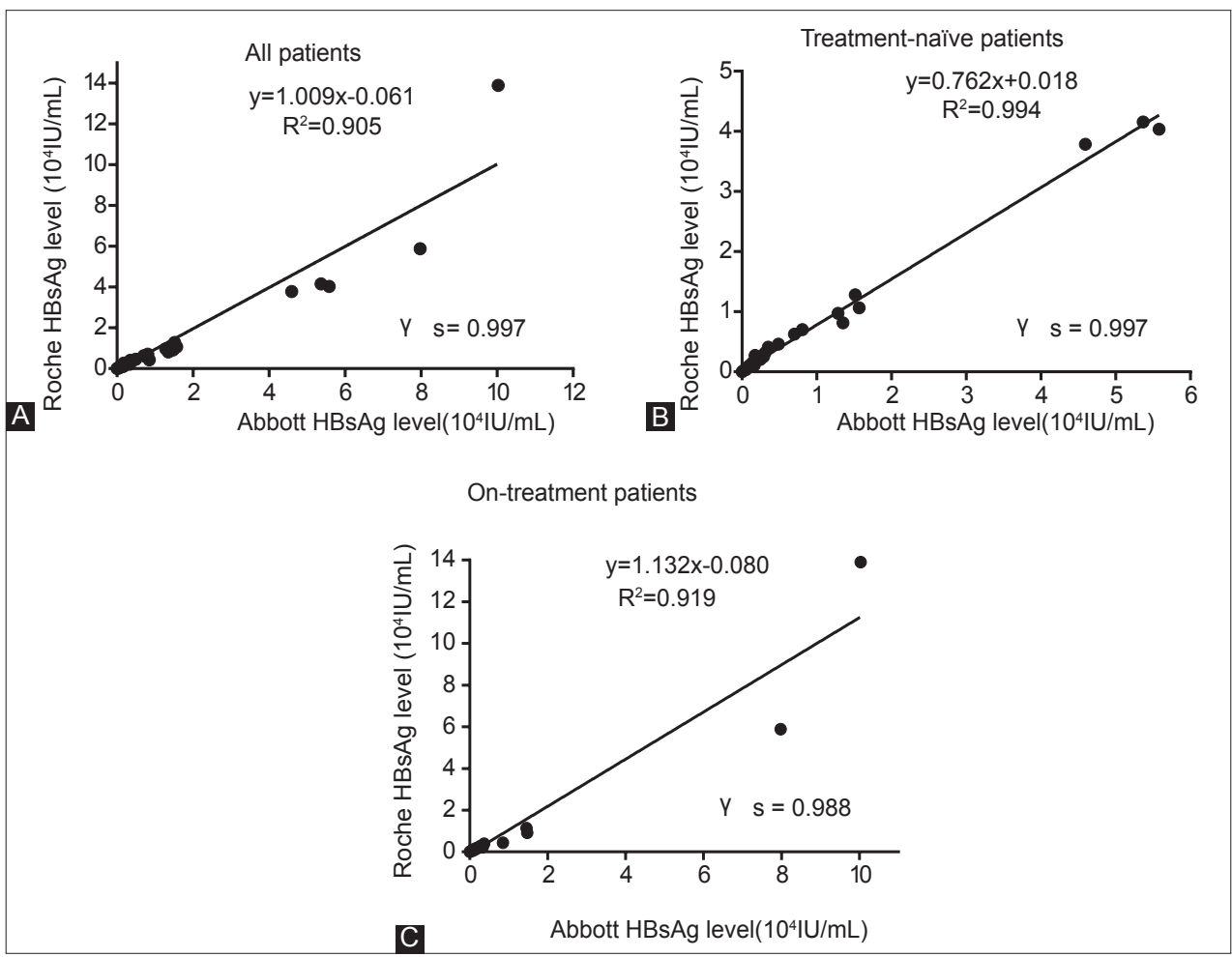

Figure 1: The association between two HBsAg quantification methods of the Abbott Architect HBsAg QT assay and Roche Elecsys HBsAg II by linear regression model and Spearman's rank test. The results of HBsAg quantification concentration showed good correlation between two methods in (A) all patients, (B) treatment-naïve patients, and (C) on-treatment patients $\left(\mathrm{R}^{2}\right.$ : Coefficient of determination in linear regression model; $\gamma_{s}$ : Spearman's rank correlation coefficient). HBsAg: Hepatitis B surface antigen.

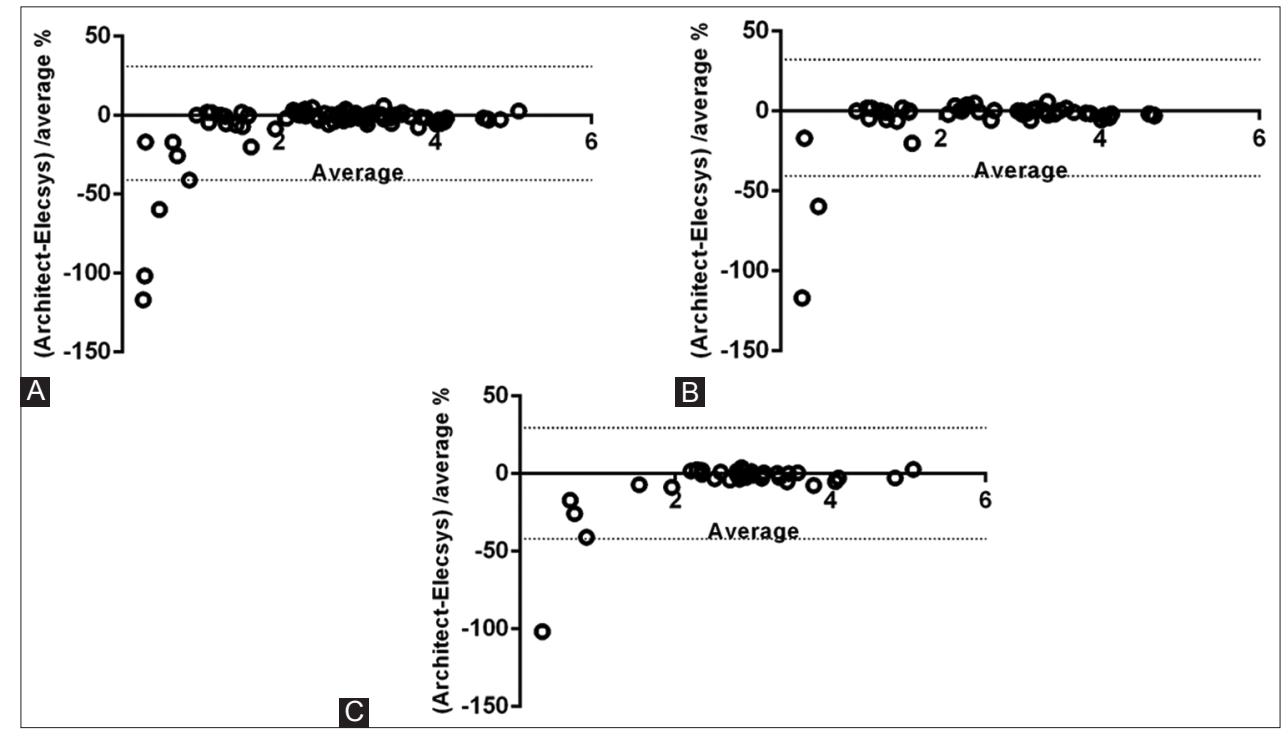

Figure 2: Correlation between the Elecsys HBsAg II and Architect HBsAg assays by Bland-Altman analysis: (A) All patients; (B) treatment-naïve patients; (C) on-treatment patients. Dashed lines represent 95\% confidence limits. HBsAg: Hepatitis B surface antigen.

(Abbott Architect and Roche Elecsys HBsAg II assay) and measured HBV DNA in both groups for further analyses as shown in Figure 4. The median HBsAg level was relatively higher in younger age (less than 40 years), but there was no statistically significant difference.

\section{DISCUSSION}

Measuring serum HBV DNA is the gold standard for monitoring viral load, but it is relatively costly and not available in some areas. The technique for detecting 


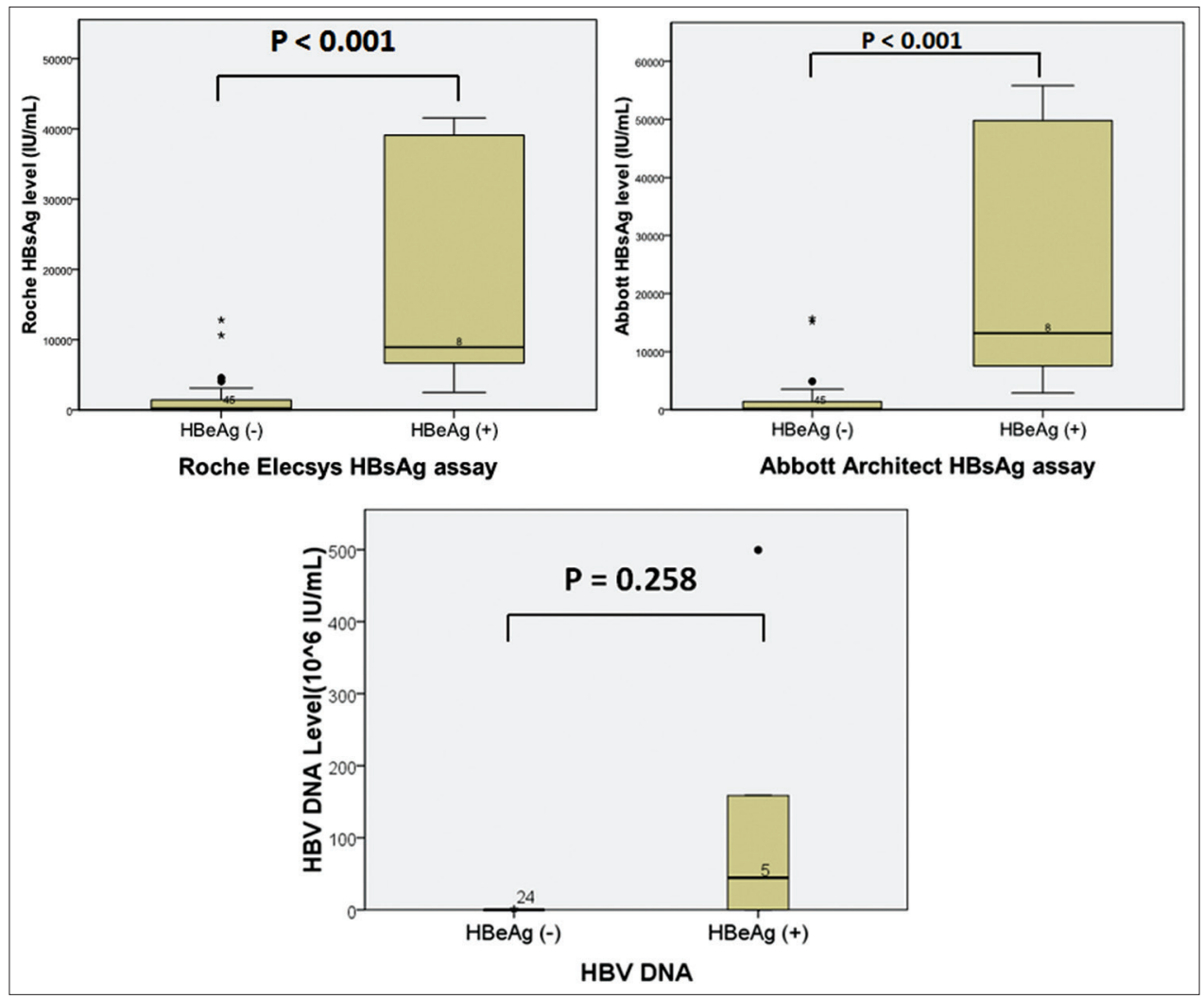

Figure 3: Abbott Architect HBsAg QT assay and Roche Elecsys HBsAg II, and HBV-DNA in treatment-naïve patients dividing into two groups of HBeAg positive and HBeAg negative. HBeAg: Hepatitis B e antigen; HBV DNA: Hepatitis B virus deoxyribonucleic acid.

Table 4: Characteristics of treatment-naïve patients in different subgroups of age

\begin{tabular}{lccc}
\hline & All patients $(n=53)$ & Age $\geqq 40$ years $(n=36)$ & Age $<40$ years $(n=17)$ \\
\hline Age, years & $48.2(27.5-71.7)$ & $54.2(40.6-71.7)$ & $36.5(27.5-39.8)$ \\
Male, $n(\%)$ & $37(69.8)$ & $25(69.4)$ & $12(70.6)$ \\
ALT $(\mathrm{U} / \mathrm{l})$ & $26(10-203)$ & $24(10-203)$ & $33(10-109)$ \\
HBeAg $(+), n(\%)$ & $8(15.1)$ & $3(8.3)$ & $5(29.4)$ \\
HBV DNA $\left(10^{6} \mathrm{IU} / \mathrm{ml}\right)^{*}$ & $0.02975(0.000033-499.5)$ & $0.00352(0.000107-158.606)$ & $0.057(0.000033-499.5)$ \\
HBsAg (IU/ml) & & & 0.241 \\
Elecsys assay & $480.2(0.05-41,565)$ & $269.3(0.05-10,638)$ & 0.047 \\
Architect assay & $513.4(0.05-55,805)$ & $251.55(0.05-15,685)$ & $2043(1.3-41,565)$ \\
\hline
\end{tabular}

" 29 of all patients $(n=53), 20$ of age more than 40 years $(n=36)$, and 9 of age less than 40 years $(n=17)$ had available HBV DNA data. Median values for age, ALT, HBV DNA, and HBsAg levels. Abbreviations: ALT: Alanine aminotransferase; HBeAg: Hepatitis B e antigen; HBV DNA: Hepatitis

B virus deoxyribonucleic acid; HBsAg: Hepatitis B surface antigen

HBsAg quantification is relatively easy and inexpensive. Recent studies indicate that $\mathrm{HBsAg}$ quantification might be a useful complement to HBV DNA quantification for clinical assessment and treatment monitoring in patients with chronic HBV infection. ${ }^{[13,14]}$ Recent studies ${ }^{[15-17]}$ and our study showed that HBsAg levels measured by the Roche Elecsys HBsAg II assay correlate well with those obtained using the established Abbott Architect assay. The Elecsys HBsAg II assay provides a reliable method for HBsAg quantitation in treatment-naïve and on-treatment patients. The HBsAg level is higher in HBeAg-positive patients, but HBV DNA level is not statistically significantly higher in $\mathrm{HBeAg}$-positive patients which may be due to smaller sample size. In addition, the HBsAg quantification level may reflect the clinical stage and liver disease progression, and a combined use of quantification of HBsAg and HBV DNA may improve the understanding of clinical course.

Although serum HBsAg qualitative test is the standard procedure for $\mathrm{HBV}$ diagnosis, however, there has recently been an increased development in the use of quantitative testing as a predictor of response to treatment. ${ }^{[18-20]}$ Clearance of HBsAg is associated with improved long-term clinical 


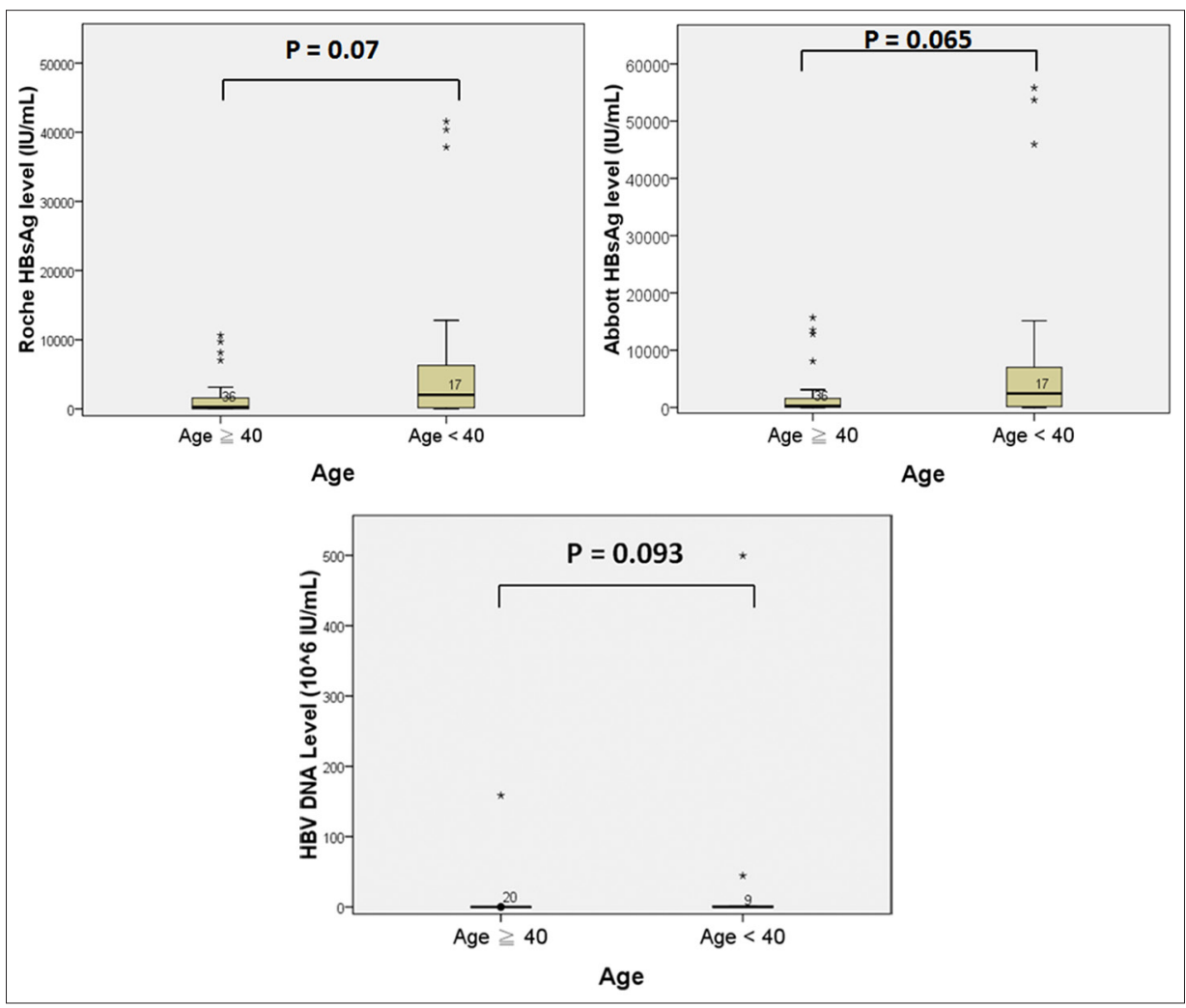

Figure 4: Abbott Architect HBsAg QT assay and Roche lecsys HBsAg II, and HBV-DNA in treatment-naïve patients dividing into age greater than or equal to 40 years (inactive phase) and age less than 40 years (immune tolerance/clearance phase). HBsAg: Hepatitis B surface antigen; HBV DNA: Hepatitis B virus deoxyribonucleic acid.

outcome, including a reduced incidence of cirrhosis and hepatocellular carcinoma and longer survival. ${ }^{[21,22]}$ Quantitative measurement of HBsAg is, therefore, likely to be of increasing importance as its use in individualization of therapy in HBV infection.

In conclusion, the Elecsys HBsAg II assay reliably determines serum $\mathrm{HBsAg}$ levels and its correlation with the Abbott Architect HBsAg assay is high. In clinical practice, Roche Elecsys II may have the possibility of improving the reproducibility of the analysis and lowering the work load of the technician, but a rigorous study design is needed to prove it. Both assays can, therefore, be applied for HBsAg quantification in clinical practice in different stages or treatment status. Moreover, HBsAg quantification may potentially provide complementary information about the deduction of the natural course in chronic hepatitis B infection. Further large-scale studies may be needed to make maximal use of HBsAg quantification to elucidate its role in clinical fields.

\section{Acknowledgments}

The authors thank Yen-Lin, Zhuang in the Liver Research Center, Chang Gung Memorial Hospital for the excellent assistance in organizing clinical and laboratory data. The authors also thank Liver Disease Prevention and Treatment Research Foundation for spiritual support. This project was funded by Chang Gung Memorial Hospital (CMRPG392183).

\section{REFERENCES}

1. Maynard JE. Hepatitis B: Global importance and need for control. Vaccine 1990;8 Suppl:S18-20.

2. Alter MJ, Hadler SC, Margolis HS, Alexander WJ, Hu PY, Judson FN, et al. The changing epidemiology of hepatitis B in the United States. Need for alternative vaccination strategies. JAMA 1990;263:1218-22.

3. Lavanchy D. Hepatitis B virus epidemiology, disease burden, treatment, and current and emerging prevention and control measures. J Viral Hepat 2004;11:97-107.

4. Wursthorn K, Jaroszewicz J, Zacher BJ, Darnedde M, Raupach R, Mederacke I, et al. Correlation between the Elecsys HBsAg II assay and the Architect assay for the quantification of hepatitis B surface antigen (HBsAg) in the serum. J Clin Virol 2011;50:292-6.

5. Sonneveld MJ, Rijckborst V, Boucher CA, Zwang L, Beersma MF, Hansen BE, et al. A comparison of two assays for quantification of Hepatitis B surface Antigen in patients with chronic hepatitis B. J Clin Virol 2011;51:175-8.

6. Tseng TC, Kao JH. Clinical utility of quantitative HBsAg in natural history and nucleos (t) ide analogue treatment of chronic hepatitis B: New trick of old dog. J Gastroenterol 2013;48:13-21.

7. Chan HL, Thompson A, Martinot-Peignoux M, Piratvisuth T, Cornberg M, Brunetto MR, et al. Hepatitis B surface antigen 
quantification: Why and how to use it in 2011-a core group report. J Hepatol 2011;55:1121-31.

8. Jaroszewicz J, Calle Serrano B, Wursthorn K, Deterding K, Schlue J, Raupach R, et al. Hepatitis B surface antigen (HBsAg) levels in the natural history of hepatitis B virus (HBV)-infection: A European perspective. J Hepatol 2010;52:514-22.

9. Nguyen T, Thompson AJ, Bowden S, Croagh C, Bell S, Desmond PV, et al. Hepatitis B surface antigen levels during the natural history of chronic hepatitis B: A perspective on Asia. J Hepatol 2010;52:508-13.

10. Liaw YF, Chu CM. Hepatitis B virus infection. Lancet 2009;373:582-92.

11. Bonino F, Ofenloch B, Melchior W, Upmeier B, Rossler D, van der Helm W. Quantitative Assessment of Serum Hbsag Level Using the Elecsys (R) Hbsag Ii Screening Assay: Results of a Feasibility Study. Hepatology 2008;48:726a.

12. Deguchi M, Yamashita N, Kagita M, Asari S, Iwatani Y, Tsuchida T, et al. Quantitation of hepatitis B surface antigen by an automated chemiluminescent microparticle immunoassay. J Virol Methods 2004; 115:217-22.

13. Sonneveld MJ, Zoutendijk R, Janssen HL. Hepatitis B surface antigen monitoring and management of chronic hepatitis B. J Viral Hepat 2011;18:449-57.

14. Liaw YF. Clinical utility of hepatitis B surface antigen quantitation in patients with chronic hepatitis B: A review. Hepatology 2011;53:2121-9.

15. Muhlbacher A, Weber B, Burgisser P, Eiras A, Cabrera J, Louisirirotchanakul S, et al. Multicenter study of a new fully automated HBsAg screening assay with enhanced sensitivity for the detection of HBV mutants. Med Microbiol Immunol 2008;197:55-64.
16. Louisirirotchanakul S, Khupulsup K, Akraekthalin S, Chan KP, Saw S, Aw TC, et al. Comparison of the technical and clinical performance of the Elecsys HBsAg II assay with the Architect, AxSym, and Advia Centaur HBsAg screening assays. J Med Virol 2010;82:755-62.

17. Jia JD, Hong M, Wei L, Zhang XX, Mao YL, Wang LL, et al. Multicentre evaluation of the Elecsys hepatitis B surface antigen II assay for detection of HBsAg in comparison with other commercially available assays. Med Microbiol Immunol 2009;198:263-9.

18. Brunetto MR, Moriconi F, Bonino F, Lau GK, Farci P, Yurdaydin C, et al. Hepatitis B virus surface antigen levels: A guide to sustained response to peginterferon alfa- $2 \mathrm{a}$ in $\mathrm{HBeAg-negative} \mathrm{chronic}$ hepatitis B. Hepatology 2009;49:1141-50.

19. Marcellin P, Brunetto M, Bonino F, Hadziyannis SJ, Kapprell HP, McCloud PI, et al. In Patients with Hbeag-Negative Chronic Hepatitis B Hbsag Serum Levels Early during Treatment with Peginterferon Alfa-2a Predict Hbsag Clearance 4 Years Post-Treatment. Hepatology 2008;48:718-9a.

20. Moucari R, Korevaar A, Lada O, Martinot-Peignoux M, Boyer N, Mackiewicz V, et al. High rates of HBsAg seroconversion in $\mathrm{HBeAg}$-positive chronic hepatitis B patients responding to interferon: A long-term follow-up study. J Hepatol 2009;50:1084-92.

21. Lok AS, McMahon BJ. Chronic hepatitis B: Update 2009. Hepatology 2009;50:661-2.

22. European Association For The Study Of The Liver. EASL clinical practice guidelines: Management of chronic hepatitis B. J Hepatol 2009;50:227-42. 